\title{
PATERNIDADE NA ADOLESCÊNCIA: ANALISANDO SEU SIGNIFICADO, OS DESAFIOS E SUAS CONSEQUENCIAS
}

\author{
PATERNIDAD EN LA ADOLESCENCIA: ANALIZANDO SU SIGNIFICADO, LOS \\ DESAFÍOS Y SUS CONSECUENCIAS
}

\author{
TEENAGE FATHERHOOD: ANALYZING ITS MEANING, CHALLENGES AND \\ CONSEQUENCES
}

\author{
Jéssica Daniele FÁVARO ${ }^{1}$ \\ Andreza Marques de Castro LEÃO ${ }^{2}$ \\ Paulo Rennes Marçal RIBEIRO ${ }^{3}$ \\ Luiz Fernando ZUIN ${ }^{4}$
}

RESUMO: A paternidade adolescente é um assunto pouco abordado socialmente e permanece praticamente inexplorado no campo cientifico, sendo escassos os trabalhos que abarcam este tema. Considerando isso, o presente estudo busca analisar na ótica dos adolescentes pais o significado que eles atribuem à paternidade, além dos desafios, consequências e implicações que ela trouxe para suas vidas, contribuindo assim para melhor compreensão da paternidade adolescente. Na análise realizada, quanto a importância que atribuem à paternidade, a fala dos entrevistados demonstrou que eles veem como realmente valioso o convívio com os filhos. Todos se consideraram envolvidos com a gravidez de suas parceiras, afirmando que ajudavam em tudo que estava a seu alcance e continuam ajudando nos cuidados com a criança. Nota-se uma alteração ao "assumir" a paternidade no que diz respeito a responsabilidade dos mesmos em ter de cuidar do aspecto financeiro da criança.

PALAVRAS-CHAVE: Adolescentes. Sexualidade. Paternidade na adolescência. Gravidez na adolescência.

RESUMEN: La paternidad em la adolescencia es un asunto poco abordado socialmente y permanece prácticamente inexplorado en el campo científico, siendo escasos los trabajos que abarcan este tema. En el presente estudio se busca analizar en la óptica de los padres adolescentes el significado que ellos atribuyen a la paternidad, además de los desafios, consecuencias e implicaciones que ella trajo para sus vidas, contribuyendo así, para una mejor

\footnotetext{
${ }^{1}$ Universidade Estadual Paulista (UNESP), Araraquara - SP - Brasil. Mestranda do Programa de Pós-Graduação em Educação Escolar. ORCID: <http://orcid.org/0000-0002-5625-9594>. E-mail: jdaniele.favaro@ gmail.com ${ }^{2}$ Universidade Estadual Paulista (UNESP), Araraquara - SP - Brasil. Docente do Departamento de Psicologia da Educação e do Programa de Pós-graduação em Educação Escolar. Vice Coordenadora e Docente do Programa de Pós-graduação em Educação Sexual. ORCID: <http://orcid.org/0000-0002-5037-4882>. E-mail: andreza_leao@yahoo.com.br

${ }^{3}$ Universidade Estadual Paulista (UNESP), Araraquara -SP -Brasil. Coordenador do Programa de Pós-Graduação em Educação Sexual. ORCID: <http://orcid.org/0000-0002-1552-5702>. E-mail: paulorennes@ fclar.unesp.br ${ }^{4}$ Universidade Estadual Paulista (UNESP), Araraquara - SP - Brasil. Mestrando do Programa de Pós-graduação em Educação Sexual. Diretor Pedagógico na escola de Educação Especial - APAE/Matão. Docente do Centro Estadual de Educação tecnológica Paula Souza-ETEC/Matão. ORCID: 〈http://orcid.org/0000-0002-2628-5919>. E-mail: nandozuin@icloud.com
} 
comprensión de la paternidad adolescente. En el análisis realizado, en cuanto a la importancia que atribuyen a la paternidad, los entrevistados demostraron que ellos ven como realmente valioso la convivencia con los hijos. Todos se consideraron involucrados con el embarazo de sus parejas, afirmando que ayudaban en todo lo que estaba a su alcance y continúan ayudando en el cuidado del niño. Se observa una enmienda al "asumir" la paternidad en lo que se refiere a la responsabilidad de los mismos en tener que cuidar del aspecto financiero del niño.

PALABRAS CLAVE: Adolescentes. Sexualidad. Paternidad en la adolescencia. Embarazo en la adolescencia.

ABSTRACT: Teenage fatherhood is socially a rarely approached subject and remains virtually unexplored in the scientific field, with few studies to cover the topic. Considering this, the present study aims to analyze the perspective of teenage fathers on the meaning they attribute to fatherhood, regarding the challenges, consequences and implications it has brought to their lives, thus contributing to a better comprehension of teenage fatherhood. In the analysis, the importance they attach to fatherhood, the speech of respondents shows that they see as really valuable the contact with their children. All of them felt involved with the pregnancy of their partners, claiming that they helped in everything in their power and continue to help in the care of the child. It is noted that the "Acknowledgement" of paternity concerns the responsibility of providing the child financially, since, in all investigated cases, the teenagers felt they need to get a job after they became fathers.

KEYWORDS: Teenagers. Sexuality. Teenage fatherhood. Teenage pregnancy.

\section{Introdução}

A adolescência é uma fase da vida do ser humano que apresenta aspectos peculiares. Segundo a Organização Mundial da Saúde (OMS), a adolescência é o período compreendido entre os 10 e os 20 anos incompletos e estaria dividida em Pré-adolescência - dos 10 aos 14 anos - e Adolescência - dos 15 aos 20 incompletos. Doescher et al. (2012) apontam que a adolescência é um período de profundas transformações, uma espécie de metamorfose que envolve o corpo, que deixa de ser infantil, e há a busca por novas referências na construção de identidade, não mais apoiada apenas na figura dos pais. Ainda segundo os autores, é nesta fase que o ser humano começa a experimentar novas e intensas emoções, vivenciar os primeiros amores, as primeiras relações sexuais, dúvidas, questionamentos, frustrações, entre outros.

No tocante ao aspecto sexual vale comentar que muitos adolescentes iniciam a vida sexual sem o devido conhecimento acerca de seus corpos, assim como do uso adequado dos métodos contraceptivos. Ademais, vários mitos cercam a primeira relação sexual, como, por exemplo, a convicção de que seria impossível engravidar nesta primeira relação, o que acaba 
contribuindo para que várias meninas, se afiançando desta ideia equivocada, engravidem ao iniciar sua vida sexual.

Em relação à gravidez na adolescência a produção bibliográfica científica existente sobre este tema é extenso, porém é frequentemente relacionado apenas à maternidade e às consequências e mudanças físicas, sociais e psicológicas que ela acarreta na vida da jovem mãe. A paternidade adolescente, por sua vez, é pouco abordada socialmente e permanece praticamente inexplorada no campo cientifico, sendo escassos os trabalhos que abarcam este tema quando comparados com os trabalhos que abrangem a maternidade, mesmo internacionalmente (LEVANDOWSKI; PICCININI, 2004). De acordo com Corrêa e Ferriani (2006), os únicos dois manuais/normatizações que foram publicados sobre a paternidade adolescente são internacionais, não havendo qualquer normatização brasileira de assistência ao pai adolescente. Este fato acaba contribuindo para fortalecer a ideia da não responsabilidade do pai adolescente em relação à criança, ideia esta que não se justifica, uma vez que a concepção da criança é de responsabilidade igual para ambos, isto é, do pai e mãe, independentemente da idade dos mesmos.

Aliás, não são apenas os estudos teóricos que são escassos, haja vista que grupos de estudos são criados nas universidades com o objetivo de discutir a maternidade na adolescência e seus métodos de prevenção, contudo, raramente criam-se grupos que discutem a paternidade e a prevenção da gravidez voltados para o adolescente do sexo masculino (NICOLELLA FILHO; ARNOLDI; ROSA, 2006). A ausência de dados sobre os pais, nos Sistemas Oficiais de Informação, relacionados aos Nascidos Vivos (SINASC) e à Saúde Reprodutiva no Instituto Brasileiro de Geografia e Estatística (IBGE), comprova a necessidade de adequação desses sistemas para a viabilização de pesquisas e ações estratégicas na prevenção da gravidez precoce e paternidade adolescente. (PAULA; et al., 2010).

A construção da nossa sociedade, com forte influência das normatizações genéricas, estabelece que a vivência da gravidez é exclusividade da mulher, dificultando a participação mais efetiva do homem nesta experiência (CORRÊA; FERRIANI, 2007). Segundo Lyra, Medrado e Lopes (2007), a espera de uma criança é um acontecimento único, vivido intensamente tanto pelo homem quanto a mulher, e muitos pais nas mais diversas idades desejam participar de todo o processo, afinal, trata-se de um compromisso a longo prazo. 
Muitas vezes até mesmo o acompanhamento do parto pelo pai é negado, mesmo com a existência de uma lei federal ${ }^{5}$ que oficialize esse direito. Segundo dados coletados pela Rede Cegonha entre maio e outubro de 2012, 64\% das 54 mil mulheres entrevistadas na pesquisa não tiveram direito ao acompanhante, muito mais por decisão das próprias unidades de saúde (56,7\% dos casos) do que por desconhecimento da lei pelas gestantes (15,3\% dos casos). A principal alegação das maternidades foi a falta de espaço físico apropriado para garantir a privacidade das gestantes e também o risco de o acompanhante acabar atrapalhando no processo $^{6}$.

Já existem algumas iniciativas que tentam garantir esse direito como, por exemplo, a campanha "Pai não é visita! Pelo direito de ser acompanhante"7 criada através de uma parceria do Grupo de Pesquisas em Gênero e Masculinidades da Universidade Federal de Pernambuco (Gema/UFPE), do Instituto PAPAI e da Rede de Homens pela Equidade de Gênero (RHEG). Tal campanha visa exigir dos governos o compromisso de gerar condições estruturais nas maternidades para que o direito ao acompanhante seja respeitado, já que não existe nenhum tipo de punição caso as maternidades descumpram a lei, fazendo com que as mães se sintam desamparadas para recorrer em favor de seu direito. Além disto, Lyra, Medrado e Lopes (2007) apontam também que é importante a presença do pai para que ele receba orientações sobre como deve ser feito o cuidado do recém-nascido e orientações também relacionadas ao aspecto sexual, de maneira a promover a saúde sexual e reprodutiva do casal.

A crescente participação feminina na esfera pública, motivada pelos movimentos feministas, está possibilitando, aos poucos, a mudança desse quadro e abrindo questionamentos sobre uma maior participação masculina no cuidado dos filhos e nas atividades domésticas. Pinheiro, Galiza e Fontoura (2009) apontam que a legislação trabalhista brasileira oferece diversos benefícios que priorizam os direitos reprodutivos das mulheres e oferecem poucas possibilidades para que os homens se comprometam com o exercício da paternidade, desconsiderando também a existência de família monoparentais masculinas e homoafetivas, compostas por dois homens. As autoras frisam ainda que, se por um lado o Brasil é um dos países que oferecem um maior tempo de licença maternidade (120 dias, podendo ser estendido para mais 60), por outro lado é um dos que oferecem o menor tempo de licença paternidade

${ }^{5}$ Lei 11.108 de 2005 alterou a Lei 8.080 de 1990, garantindo às parturientes o direito à presença de acompanhante durante o trabalho de parto, parto e pós-parto imediato, no âmbito do Sistema Único de Saúde (SUS). A lei foi sancionada em 7 de abril de 2005 e passou a vigorar desde então.

${ }^{6}$ Segundo reportagem publicada no dia 28 de janeiro de 2013 no jornal O Estado de São Paulo.

${ }^{7}$ Disponível em: http://institutopapai.blogspot.com.br/p/campanha-pai-nao-e-visita-pelo-direito.html 
(apenas 5 dias), impossibilitando que os pais exerçam o mesmo direito garantido as mães, o de cuidar de suas crianças.

No entanto, frequentemente o pai é apresentado como um sujeito sem capacidades necessárias para cuidar de uma criança, e a mídia colabora muito com essa visão, já que são raras as propagandas de produtos de bebês onde é apresentada a imagem do pai como cuidador, e se ele aparece, é, em geral, apresentado como um "estepe" em ocasiões em que a mãe não está presente, se mostrando inapto a desempenhar sua função. Medrado (1997, p. 80) afirma que na mídia a figura paterna está presente com mais frequência na função de educar moralmente e garantir o futuro dos filhos financeiramente, e também na figura do "pai pastelão", presente no imaginário obstétrico-puericultor contemporâneo, como sendo todo desajeitado no trabalho de parto.

Lyra, Medrado e Lopes (2007, p. 10) afirmam que é importante saber que os homens não são incapazes de cuidar, e para a mudança desse cenário é preciso expor os garotos ainda na infância a outros valores e modelos de masculinidade, não reprimindo o garoto quando ele tenta incluir objetos do lar em suas brincadeiras ou quando ele brinca de casinha, afinal cuidado é uma habilidade que se aprende ao longo da vida.

Cabral (2002) alega que muitos jovens encaram essa nova fase como uma passagem para a vida adulta, uma vez que a partir desse momento deverão ter maior responsabilidade, já que passam a ser responsáveis por outra pessoa além de si mesmos. Vários psicólogos apontam que um dos benefícios da paternidade precoce é o fato dos garotos adquirem uma responsabilidade diferenciada de seus colegas, pois a tendência é que ele se exponha menos a uma vida adolescente de excessos, uma vez que a lembrança do filho o colocará nos eixos, e este fato também pode contribuir para que o jovem consiga um emprego, pois, segundo Ricardo Bevilacqua, diretor geral da Case Consulting, companhia especializada na colocação de profissionais no mercado de trabalho, o fato do garoto ser pai pode ser visto como um ponto favorável na entrevista, uma vez que as empresas confiariam mais nesse jovem, acreditando que seu senso de obrigação faria com que ele não causasse problemas e se concentrasse mais na sua função (AMENDOLA, 2006).

É interessante salientar ainda que nem sempre se pode associar gravidez na adolescência a gravidez não planejada, pois alguns adolescentes realmente desejam a vinda de uma criança e param com o uso dos métodos contraceptivos deliberadamente para que esse desejo se torne possível, mesmo sem a aprovação ou conhecimento pelos pais do jovem casal (CABRAL, 2009). As explicações possíveis para esse desejo de serem pais numa idade jovem são diversas, incluindo amor entre os parceiros, antídoto à anomia, autoproteção contra a sedução do tráfico 
e do crime, entre outras, sugerindo que a gravidez em idades jovens exige contextualizações mais específicas por se tratar de um fenômeno heterogêneo, incluindo a discussão sobre a paternidade na adolescência (VILLELA; DORETO, 2006).

Amendola (2006) aponta que muitas vezes o jovem nega a realidade, pois não acredita que isso poderia acontecer com ele, outros reagem de forma mais acirrada, questionando a namorada se realmente seriam o pai da criança e até mesmo se perguntando se a namorada não teria engravidado de propósito. Para Lyra (citado por AMENDOLA, 2006), esta seria uma reação machista incentivada pela mídia e adquirida por repetição, uma vez que famosos políticos, jogadores de futebol, cantores, entre outros, muitas vezes reagem dessa forma, lançando suspeitas sobre o comportamento feminino.

Os estudos sobre a adolescência e sexualidade apontam a necessidade de uma abordagem clara e livre de preconceitos, que envolva a família, escola, comunidades religiosas, ambientes prestadores de assistência a saúde e de formação profissional habilitada e capacitada, sendo necessária também a implementação de estratégias que permitam aos adolescentes (de ambos os sexos) conscientizar-se sobre a importância que envolve a saúde sexual e reprodutiva e o diálogo aberto sobre suas dúvidas e vivências (VIEIRA; et al., 2006).

Dentre este cenário, é preciso incluir a perspectiva masculina como elemento importante na saúde reprodutiva, uma vez que a paternidade adolescente é um assunto que gera desafio para ser compreendido (CABRAL, 2003). Outrossim, se faz necessário pensar em uma educação sexual consistente voltada a orientar e instigar a reflexão dos adolescentes acerca da importância da prevenção da gravidez e das DSTs.

Neste interim, é importante também analisar como se dá a experiência juvenil destes jovens pais, uma vez que eles próprios encaram essa nova etapa de suas vidas como a passagem para a vida adulta, ou seja, jovens adolescentes de 10 a 19 anos considerando-se adultos e sem o apoio social e psicológico necessário para enfrentar esse desafio, de maneira que saibam como exercer da melhor forma possível o papel de pai, papel relevante, sobretudo, pensando em contribuir no desenvolvimento e criação do bebê.

\section{Metodologia}

A presente pesquisa é de caráter qualitativo, realizada através de entrevista semiestruturada. A opção pela entrevista semiestruturada se deu por ser um profícuo instrumento, pensando na história de vida dos sujeitos. Segundo Heilborn, Cordeiro e Menezes (2009) é um processo que envolve empenho de ambos para se expressarem na "mesma língua", além de que 
os dados que podem ser obtidos através dela não dizem respeito apenas a fala, mas também a uma série de pequenas informações transmitidas pelos gestos corporais, reações, pausas, sorrisos e demais expressões que podem integrar valiosamente o conjunto de dados para a análise. Deste modo foi elaborado um roteiro de entrevista que serviu de guia para a mesma, mas deixando a pesquisadora livre para utilizá-lo conforme sua necessidade, já que permite a posterior ampliação dos questionamentos, conforme as informações vão sendo fornecidas pelo entrevistado. Além disso, foi utilizado o gravador de voz, de modo que foi possível o registro das entrevistas para posterior transcrição integral das falas.

A pesquisa foi aprovada no Comitê de Ética em pesquisa da Faculdade de Ciências e Letras de Araraquara, sob o número 988.660, e foram respeitados os princípios éticos dispostos na Resolução CNS 196/96.

\section{Análise dos resultados}

O estudo foi realizado com 7 jovens que se encaixavam nos requisitos pré-estabelecidos, ou seja, tiveram filhos antes dos 20 anos completos. A tabela a seguir apresenta as informações gerais dos participantes, destacando os seguintes itens: idade atual, idade à época da gravidez, escolaridade, exercício de atividade remunerada e relacionamento atual com a mãe de seu filho.

Tabela 1 - Dados dos participantes

\begin{tabular}{|c|c|c|c|c|c|c|}
\hline Pais & $\begin{array}{c}\text { Idade } \\
\text { atual }\end{array}$ & $\begin{array}{c}\text { Idade à } \\
\text { época da } \\
\text { gravidez }\end{array}$ & Escolaridade & $\begin{array}{c}\text { Exerce } \\
\text { atividade } \\
\text { remunerada }\end{array}$ & $\begin{array}{c}\text { Número } \\
\text { de filhos }\end{array}$ & Relacionamento \\
\hline E1 & 23 & 17 e 19 & $\begin{array}{c}\text { E. Superior } \\
\text { incompleto }\end{array}$ & $\operatorname{sim}$ & 2 & Não mantém \\
\hline E2 & 18 & 16 & $\begin{array}{c}\text { E. Médio } \\
\text { incompleto }\end{array}$ & não & 1 & Mantém \\
\hline E3 & 22 & 19 & $\begin{array}{c}\text { E. Superior } \\
\text { incompleto }\end{array}$ & $\operatorname{sim}$ & 1 & Não mantém \\
\hline E4 & 19 & 18 & $\begin{array}{c}\text { E. Médio } \\
\text { Completo }\end{array}$ & $\operatorname{sim}$ & 1 & Mantém \\
\hline E5 & 24 & 15 & $\begin{array}{c}\text { E. Médio } \\
\text { Completo }\end{array}$ & $\operatorname{sim}$ & 1 & Não mantém \\
\hline E6 & 25 & 19 & $\begin{array}{c}\text { E. Superior } \\
\text { Incompleto }\end{array}$ & não & 1 & Não mantém \\
\hline E7 & 21 & 17 & $\begin{array}{c}\text { E. Médio } \\
\text { Completo }\end{array}$ & sim & 1 & Não mantém \\
\hline
\end{tabular}

Fonte: Elaboração própria.

A análise foi dividida entre os quatro temas propostos no roteiro de entrevista: Educação Sexual, DSTs e Métodos contraceptivos, Gravidez e relacionamento e Paternidade.

\section{Educação sexual}


Todos os entrevistados afirmaram que tiveram acesso à educação sexual, sendo que um dos adolescentes (E2) afirmou conhecer "a maioria", que segundo ele são as doenças e os cuidados que devem ser tomados para evitá-las. E3 se considerou bem informado, porém salientou que algumas coisas poderiam ser melhoradas, afirmando que existe muita informação e pouco foco na educação sexual, como é possível verificar em sua fala.

E3: olha, até considero bem informado sim, mas assim eh, da pra melhorar isso assim no geral, jovens, ter uma conversa um pouco mais séria a respeito disso porque, o sexo embora seja uma coisa muito primitiva, é uma coisa muito séria, né? Porque eu tive sorte de ter sido pai, Deus foi muito bom comigo [...] mas eu poderia ter pego uma doença, né? Isso aí eu acho que poderia melhorar assim, principalmente nessa era da tecnologia, né? Eh, tem muita informação e pouco foco, então é onde a molecada se perde, e se perde mesmo.

O jovem E5 afirmou que na época da gravidez tinha pouco conhecimento, como podemos observar através de sua fala.

E5: acho que parte por falta de informações né? e...naquela época eu não tinha todo o conhecimento que eu tenho hoje, então muita coisa a gente não sabia...na época eu tinha quinze anos e ela tinha catorze, então meio que tava descobrindo as coisas né? tanto eu quanto ela a gente sabia muito pouco.

Sobre o local de onde teria advindo a educação sexual, a grande maioria (cinco entrevistados) dos jovens mencionou a família e três deles mencionaram também a escola, sendo que apenas E2 mencionou centros de saúde.

Ao serem questionados com quem se sentiam mais à vontade para conversar sobre sexo, E1, E2 e E4 afirmaram preferir conversar com a namorada, sendo que E2 e E4 apontaram também a mãe. Já E3 respondeu que, apesar de conversar com amigas e a mãe sobre o assunto, se sentia mais à vontade com qualquer figura masculina. E5 apontou que se sentia mais à vontade conversando com amigos, da mesma forma que E6 e E7.

\section{DSTs e métodos contraceptivos}

Foi apresentada aos jovens uma tabela com doze métodos contraceptivos para que eles apontassem quais desses métodos tinham conhecimento. Todos mencionaram conhecer a camisinha masculina, a pílula anticoncepcional e o preservativo feminino. A abstinência periódica/tabelinha, o DIU, o diafragma e o adesivo anticoncepcional foram os menos conhecidos. 
A tabela 2 apresenta os doze métodos contraceptivos apresentados e quais dos pais manifestaram conhecê-los.

Tabela 2 - Conhecimento dos métodos contraceptivos pelos participantes

\begin{tabular}{|ll|}
\hline MÉTODOS CONTRACEPTIVOS & PAIS \\
Pílula anticoncepcional & E1, E2, E3, E4, E5, E6 e E7 \\
Contracepção injetável & E1, E2, E4 e E7 \\
Pílula do dia seguinte & E1, E3, E4, E5, E6 e E7 \\
Dispositivo intra-uterino (DIU) & E2 e E7 \\
Preservativo masculino & E1, E2, E3, E4, E5, E6 e E7 \\
Diafragma & E2 \\
Espermicidas & E1 e E2 \\
Anel vaginal & E1 e E2 \\
Abstinência periódica/tabelinha & E5 e E7 \\
Preservativo feminino & E1, E2, E3, E4, E5, E6 e E7 \\
Métodos cirúrgicos & E1, E2, E3, E4 e E7 \\
Adesivo anticoncepcional & E3 \\
\hline
\end{tabular}

Fonte: Elaboração própria.

No concernente às Doenças Sexualmente Transmissíveis (DSTs), a maioria dos jovens afirmou conhecê-las e fazer uso de preservativos masculinos para evitá-las, apenas E5 classificou seu conhecimento como "pouco". No entanto, ao serem questionados se faziam uso de algum método para evitá-las atualmente, apenas E3 e E7 afirmaram usar camisinha, sendo que os outros pais afirmaram não fazer uso de nenhum método. No caso dos jovens E1, E2 e $\mathrm{E} 4$, podemos entender que isso se deva ao fato dos três estarem em relacionamentos estáveis e, como afirmam Cano e Ferriani (2000), muitos jovens deixam os métodos contraceptivos a partir do momento que passam a confiar em seus parceiros em função do tempo prolongado do namoro, pois acreditam que com a evolução temporal o relacionamento se torna estável e fiel.

A fala de um dos entrevistados aponta que ele tem plena consciência de ter se arriscado ao manter relações sexuais sem o uso de camisinha.

E3: eh, eu tive sorte em ser pai, mas tem doenças assim, sexualmente transmissiveis, tem de monte e você não é pela beleza que você vai saber se ela tem ou não.

Já E6, quando indagado se não sentia necessidade de usar algum método de prevenção contra as DSTs, afirma que prefere não pensar sobre o assunto, evidenciando a necessidade de um maior entendimento sobre o que os métodos contraceptivos representam para os jovens e se a possibilidade de contrair doenças sexualmente transmissíveis não é de fato uma preocupação em suas vidas. 
Sobre a necessidade de conversar com alguém antes da primeira relação sexual, dois entrevistados afirmaram terem conversado (E1 e E3). Os demais não tiveram nenhuma conversa, e E2 e E4 afirmaram não ter sentido essa necessidade, ao contrário de E5, que salientou sentir essa necessidade, apesar de não ter tido essa oportunidade.

A fala de um deles revela que a conversa sobre sexo sempre foi muito aberta em sua casa, porém que isto não evitou a paternidade.

E3: [...] já antes de acontecer, meu pai minha mãe meu irmão, sempre conversávamos, eu sempre tava sabendo o que tava fazendo [...] meu pai quando eu tinha onze, doze anos ele já chegou a pegar banana, mostrar como que colocava camisinha, né? E aí tá aí né? Eu não aprendi direito ((risos))

Já a fala de outro jovem evidencia que conversar sobre sexualidade ainda é um tabu dentro da família.

E7: em casa a gente nunca conversou sobre essas coisas, tinha vergonha de chegar e perguntar alguma coisa sabe? ficava pensando o que meus pais iam pensar...então eu sempre conversei mais com os amigos mesmo né? mas acaba que ninguém sabe direito das coisas, tem muita informação errada, umas coisas que depois a gente descobre que fazia errado...

\section{Gravidez e relacionamento}

Dos adolescentes entrevistados mais da metade não mantêm mais o relacionamento com a mãe de seus filhos. Isso se deve ao fato de que, em geral, o pensamento dos jovens tende a mudar muito na fase da adolescência, o que pode significar a descoberta de novos gostos e rumos de vida que não condizem mais com o relacionamento com a mãe de seus filhos. Segundo o professor Ailton Amélio da Silva, citado por Amendola (2006), a paternidade adolescente tende a criar uma relação estável, mas de curta duração, justamente por essas mudanças que são características da adolescência. No caso dos entrevistados, os únicos que ainda permanecem com as parceiras são aqueles cuja idade atual está mais aproximada da idade com que tiveram seus filhos.

Quando questionados sobre a duração do relacionamento quando a gravidez ocorreu, E1, E2, E4 e E7 afirmam que tinham cerca de seis meses de convívio, E6 possuía 4 meses de relacionamento, E3 não mantinha nenhum relacionamento e E5 “ficava sem compromisso" há cerca de um mês antes da gravidez. As falas revelam que em dois casos (E2 e E3) a gravidez ocorreu na primeira relação e em quatro casos não houve uso de nenhum método contraceptivo. Quando indagados sobre o motivo que os levaram a não fazer uso de nenhum método 
contraceptivo, E1 alegou não saber responder porque não utilizaram, já que costumavam utilizar sempre, E3 afirmou que a parceira assegurava que não podia engravidar, E2 e E7 disseram que não esperavam que a relação sexual aconteceria naquele dia e estavam despreparados, E5 aponta a falta de conhecimento devido à pouca idade na época (15 anos dele e 14 da parceira) e a fala de E6 aponta que eles nunca utilizaram nenhum método contraceptivo durante o tempo de relacionamento.

Em relação ao relacionamento atual com a mãe da criança, a fala dos participantes revela que houve mudanças ocorridas após a gravidez.

E2: ah... Assim, apareceu uma responsabilidade, né? Não era como antes, assim a gente se divertia pra caramba, não é mais assim... Ela ficou um pouquinho mais chata também, né? ((risos)) é isso.

E3: eh... NÃO éfácil, porém temos uma harmonia... Boa ((frase exclamativa)) bem gostosa sadia, em prol da criança, né? Porque, não pensamos exclusivamente em mim ou nela, é sempre a criança [...] a gente preza muito essa harmonia pra que ela não sinta nada assim, eh, de desconforto em relação ao ambiente, né? Até porque, eh, eu acredito que quando há muito conflito entre os pais isso prejudica somente a criança [...]

E1: já tínhamos terminado o namoro e, ao invés de seguir minha vida, como em outros relacionamentos que acabam, criei um laço de amizade com ela, por ser mãe de minha filha, dando toda assistência pré-natal e também pós.

E6: [...] evidente que muda né? você vê seu filho nascendo na barriga da pessoa, ela cuidando assim, o carinho aumenta assim mas não sei.

E7: ah, muda bastante né? porque agora tem uma criança pra cuidar e não é uma coisa que você tinha planejado. A cabeça dos dois muda, era o nosso primeiro namoro, você ainda não sabe se quer ficar com aquela pessoa...tá conhecendo e daí agora vocês tem uma ligação pra sempre, daí tem a pressão de ficarem juntos mesmo não se gostando mais pro bem da criança.

Para E2, que permanece com a mãe da criança, a convivência teria mudado, uma vez que já não se divertem mais como antes, devido a nova responsabilidade que surgiu em suas vidas, e E4, que também permanece com a mãe de seu filho, aponta que dá mais atenção a parceira. Já para os outros jovens, que não mantêm mais o relacionamento, este se fortaleceu, criando um vínculo de amizade em prol da criança, mesmo que seja difícil, como afirma o jovem E3.

Concernente ao planejamento da gravidez, apenas E4 afirmou que a gravidez teria sido planejada, pois ambos desejavam um filho. A maioria dos entrevistados afirmou que não havia sido planejada e nenhum atribuiu a responsabilidade da gravidez apenas à parceira. É 
interessante observar que um dos entrevistados afirma que, mesmo sabendo que o sonho da parceira era ser mãe, ambos sabiam o que estavam fazendo.

E3: ah essa responsabilidade... Ah... eram os dois...os dois sabiam o que tavam fazendo não adianta, por mais que ela sempre, o sonho dela eu sabia que era ser mãe mas, os dois sabiam o que tavam fazendo não tem como culpá-la [...]

Outro jovem trás para si toda a responsabilidade da gravidez, todavia sua fala nos sugere que ele teria assumido essa responsabilidade para acalmar a parceira que estaria num momento de crise.

E2: é assim é, quando ela soube que estava grávida, ela já entrou logo em depressão, queria se matar, não queria contar pra mãe porque achava que a mãe ia matar ela [...] no começo foi mil pedras, assim eu falei: "oh calma, a gente vai cuidar do bebê a gente vai se virar, eu arrumo um emprego, eu sustento o bebê, se apenas vai cuidando dele que eu não vou ter tempo vinte e quatro horas pra cuidar dele" então eu assumi a responsabilidade total do bebê, assim, eu cuido do bebê, eu quero ter esse filho, acontecer aconteceu, o erro foi meu, foi meu, eu QUERO ((ênfase)) ter esse filho.

Porém, quando questionados sobre o porquê a gravidez teria ocorrido, as falas de E1, "porque ela não utilizava nenhum método contraceptivo" e E3, "por ela querer muito (uma criança)", apontam contradição na afirmação anterior de que para os entrevistados a responsabilidade seria igual de ambos, uma vez que jogam para a mãe a responsabilidade de não se prevenir ou querer muito uma criança.

\section{Paternidade}

Cinco entrevistados, E1, E3, E4, E6 e E7 afirmaram que não houve grandes mudanças em relação ao modo como imaginavam seus futuros com a chegada da paternidade, uma vez que E1, E3 e E4 já trabalhavam e a paternidade acabou fortalecendo a ideia de responsabilidade e dando força a mais para alcançar suas perspectivas de vida, e E6 tinha pretensão de continuar seus estudos, projeto que se concretizou mesmo com a paternidade. Já E7 afirma que imaginava que teria filhos bem mais tarde, porém isso não afetou muito seu futuro, uma vez que a paternidade lhe trouxe maior foco para conseguir um emprego e fazer um curso profissionalizante.

A fala de E3 aponta que sua situação só melhorou na empresa em que trabalha e que a filha seria o motivo de sua melhora de vida. 
E3: [...] quando eu descobri que ia ser pai eu já trabalhava e inclusive no mesmo emprego que estou...até melhorou as coisas pra mim [...] pra ser sincero, ela veio (( a filha)) pra por um eixo, um eixo pra minha vida caminhar porque [...] era perdidão mesmo [...] minha perspectiva de vida era só zoar só zoar, [...] não queria responsabilidade não queria nada... Até que, como pra mim nada é por acaso, ela veio pra substituir isso aí.

Estas falas evidenciam como muitos jovens encaram a paternidade como uma passagem para a vida adulta, pois ela pede maior responsabilidade (CABRAL, 2002), e veem no nascimento da criança uma oportunidade de se firmar (ARILHA, 2001).

O jovem E2, que ainda não trabalha, afirma que a vida mudou completamente, já que a necessidade de conseguir um emprego para que possa sustentar a criança se tornou primordial em sua vida.

E2: Mudou completamente ((frase exclamativa)) [...] minha perspectiva de vida antes era o que? Era juntar dinheiro, morar com a minha mãe ainda, não por ser filhinho de mamãe também, né? Mas assim, juntar dinheiro pra conseguir um carro, uma casa, trabalhar, assim, não tava procurando ((emprego )) com o desespero que eu to procurando agora, trabalhar mais tarde e terminar meus estudos primeiro, fazer faculdade [...].

A paternidade na adolescência pode provocar uma maior necessidade de entrar no mercado de trabalho e muitas vezes por essa necessidade os jovens abandonam a escola (PAULA et al., 2010). No caso do entrevistado acima, ele pretende continuar os estudos e espera conseguir conciliar o trabalho e a escola.

E5, que dos entrevistados foi o qual teve seu filho com menos idade, aponta que a vida também mudou completamente, pois agora ele pensa no filho para todas as decisões de sua vida, até mesmo sobre a possibilidade de um novo relacionamento amoroso.

E5: ah mudou completamente, que a partir do momento que eu descobri que ia ser pai então aí eu deixei de pensar primeiro em mim pra pensar primeiro nele...então tudo que eu vou fazer, que eu vou pensar é primeiro nele, então de dar uma boa educação pra ele, poder dar o que ele precisa, então acho que depois desse dia que eu descobri, [...] qualquer decisão que eu ia tomar eu tinha que pensar que ia afetar ele independente do que seja, profissional, pessoal, tanto um outro relacionamento com outra pessoa, tudo tinha que pensar nele primeiro.

Quando perguntados sobre a reação que tiveram no momento da descoberta da gravidez, E2 afirmou que permaneceu muito calmo, E1 e E7 dizem que suas reações foram de choque, E3 não conseguia acreditar que seria pai, situação que mudou apenas com o resultado do exame de DNA, E4 diz ter ficado contente, afinal ele e a parceira desejavam ter o filho, E5 afirma que 
chorou muito com a descoberta, possivelmente pelo choque da nova situação e E6 afirma que permaneceu tranquilo com a notícia.

Quanto a importância que atribuem à paternidade, a fala dos entrevistados demonstra que eles veem como valioso o convívio com os filhos. E2 mencionou que, pelo fato de não ter tido um pai, pretende dar todo o apoio que ele não teve ao seu filho.

E2: [...] eu não tive um pai... Não porque ele morreu, é assim, ele pensava que eu não era filho dele [...] isso que eu quero dar pro meu filho, o pai que eu não tive, eu quero ser o pai perfeito pra ele, ajudando, acompanhando ele, dando apoio total, tudo, um sonho dele eu quero o que? Dar força até o final... Até ele conseguir.

Outro jovem aponta a importância do pai como exemplo para a vida do filho.

E5: acho que o pai...eu acho que eu sou o exemplo pra ele, então tudo que eu fizer de bom e fazer de ruim é o exemplo que ele vai ter pra ele fazer na vida dele, então eu tenho que saber como conversar com ele, o que eu vou passar pra ele, como que eи vou passar porque eи sei que eи sou o exemplo dele.

E outra fala expressa ainda o encantamento de um dos pais com a paternidade.

E3: eh eu, posso falar que, ixe é magico, é único, é muito especial ser pai, o abraço, o te amo inesperado da criança, aquele abraço caloroso, só sendo pai pra saber e mãe só sendo mãe pra saber e assim, eu me tornei um homem mesmo.

Segundo Paula et al. (2010), a paternidade por adolescentes pode ser uma experiência positiva, plena de emoções. As autoras afirmam ainda que eles podem ser bons pais, independente da fase de transição pela qual estão passando.

Todos os jovens se consideraram envolvidos com a gravidez de suas parceiras, afirmando que ajudavam em tudo que estava a seu alcance e continuam ajudando nos cuidados com a criança. E3 afirmou que, à época da gravidez, não tinha certeza se era realmente o pai da criança, uma vez que a mãe de seu filho se envolvera com outro rapaz no mesmo período e não estava certa de qual dos dois teria engravidado. De qualquer forma, ele conta que foi até o hospital para acompanhar o parto e afirma ter ajudado durante toda a gravidez, porém afiança que se soubesse que o filho era seu, desde o princípio, teria dado uma assistência maior e se envolvido mais com a gravidez.

O caso de E5 contrasta dos demais por seu filho morar com ele atualmente e não com a mãe, como ocorre mais frequentemente. Sua fala é reveladora da situação e dos motivos que o teriam levado a ficar com a guarda da criança. 
E5: [...] hoje atualmente ela tem outra filha tal, mas a cabeça dela não evoluiu muito, então ela gosta mais de sair, de curtir, eu já sou mais caseiro [...] não querendo falar que eu sou melhor pai que ela melhor mãe...mas eu acho que eu foquei mais, eu tenho que ser pai então eu tenho que em termos deixar a minha vida e fazer a vida de pai...e viver pra ele...só que ela não, ela já gosta mais de balada então ela não gosta dessa coisa de presa de ter ali horário de não poder sair porque tem que ficar...e mesmo quando a gente morava juntos, então ela saía, ela ia pro baile, então eu quem ficava com ele, desde os primeiros meses dele, quem ficou mais junto com ele fui eu.

[...] assim, ele vê ela mais de final de semana...então tem vez que ele não quer ir, porque hoje ele é muito apegado em casa, mas ele vai mais em final de semana...

Amendola (2006) aponta que o mais comum, quando a criança não permanece com a mãe, é ficar sob cuidados de outra pessoa e o pai sendo obrigado a pagar a pensão alimentícia para o filho, o que não é o caso de E5, que afirma dar todos os cuidados ao seu filho desde o nascimento, expondo com orgulho que foi ele quem deu sua primeira refeição.

Lyra, Medrado e Lopes (2007, p. 10) afirmam que em nossa sociedade o ato de cuidar, em geral, é visto como "coisa de mulher". Ainda segundo os autores é importante saber que os homens não são incapazes de cuidar, e para a mudança desse cenário é preciso expor os garotos ainda na infância a outros valores e modelos de masculinidade, não reprimindo o garoto quando ele tenta incluir objetos do lar em suas brincadeiras ou quando ele brinca de casinha, afinal, cuidado é uma habilidade que se aprende ao longo da vida.

Sobre o desejo de terem mais filhos, a maioria dos jovens afirma que pretendem, no entanto planejam isso para o futuro, quando possuírem maior estabilidade financeira e possibilidade de sustentá-los. Já E6, que também deseja ter mais filhos, afirma não fazer planejamentos, pois considera estranha a ideia de delinear futuras ações da vida. Apenas E5 diz não pretender ter mais filhos, pois agora pretende crescer profissionalmente, proporcionando uma vida melhor para ele e para o filho, e acredita que tendo outro filho teria que começar tudo novamente, pois uma criança pequena necessita de mais atenção e cuidados.

\section{Considerações finais}

A adolescência é um período com diversas transformações na vida dos jovens, tanto físicas como emocionais, e muitas vezes é também o período de iniciação sexual, que ocorre frequentemente sem o devido conhecimento acerca dos métodos contraceptivos e prevenção de doenças sexualmente transmissíveis. Para o adolescente, todas essas mudanças são experiências novas, que geram dúvidas e nem sempre ele se sente à vontade para conversar sobre este assunto com seus pais e professores, o que faz com que converse apenas com amigos de idade 
aproximada, que podem acabar reproduzindo ideias, mitos e conceitos errados, que podem levar a uma gravidez na adolescência.

$\mathrm{Na}$ presente pesquisa foi possível perceber que os jovens têm conhecimento sobre alguns métodos contraceptivos, porém geralmente deixam de fazer uso deles quando estão em relacionamentos considerados estáveis. Muitos jovens ainda mantêm a crença de que a gravidez é uma coisa que aconteceria apenas com "os outros" e não em sua vida. Por este motivo se faz necessária uma educação sexual livre de preconceitos, que procure esclarecer quaisquer questionamentos dos adolescentes em relação à contracepção, gravidez e as principais dúvidas que surgem nesta época de suas vidas, algo realmente pensado para eles, com uma linguagem acessível e atraente. Muitos pais e professores acreditam que o conversar sobre sexualidade na escola pode fazer com que a entrada na vida sexual seja acelerada, o que é um equívoco, uma vez que com o conhecimento no assunto os jovens saberão se prevenir melhor e poderão identificar situações de risco.

Ademais, percebe-se ainda que nem sempre a gravidez pode ser caracterizada como indesejada, uma vez que em um dos casos o adolescente afirmou que ele e a parceira queriam um filho. Em todos os outros 6 casos, porém, a gravidez foi acidental. Seriam muito interessantes mais estudos a fim de entender os casos onde a gravidez é planejada por pessoas tão jovens e quais os motivos que levaram a esse planejamento.

No tocante à paternidade significar um aumento da responsabilidade dos jovens, como é indicado por estudos anteriores, isto também foi comprovado pelo presente estudo, uma vez que todos os adolescentes manifestaram que se sentem mais responsáveis após a descoberta da gravidez, e alguns até mesmo apontam uma melhora em suas vidas. Essa maior responsabilidade se dá pela necessidade de conseguir sustentar a si mesmo e sustentar seus filhos, uma vez que é o que a sociedade e seus familiares esperam deles.

O cuidado ainda é frequentemente atribuído às mães, porém no estudo pudemos conhecer um jovem que tem a guarda legal de sua criança e que é quem desempenha a maior parte de seu cuidado desde seu nascimento. Isso é uma prova de que os homens devem ter sua capacidade de cuidar reconhecida e respeitada, tendo os mesmos deveres e direitos atribuídos às mães. Faz-se necessário que a sociedade reconheça o papel do pai como cuidador, não atribuindo esta tarefa apenas a mãe ou às mulheres em geral como "instinto maternal".

Em suma, pode-se ver como são valiosos esses relatos dos pais adolescentes que muitas vezes acabam não sendo ouvidos pela sociedade, e por este motivo acreditamos serem necessários mais estudos que abarquem o tema, de modo que o "cuidar" do pai se torne algo comum na sociedade, nos meios de comunicação e nas famílias. 
AGRADECIMENTOS: À Fundação de Amparo à Pesquisa do Estado de São Paulo (FAPESP).

\section{REFERÊNCIAS}

AMENDOLA, G. Meninos Grávidos: O drama de ser Pai adolescente. 1. ed. São Paulo: Albatroz, 2006.

ARILHA, M. Homens: entre a "zoeira" e a "responsabilidade". In: ARILHA, M.; RIDENTI, S. G. U.; MEDRADO, B. (org.). Homens e masculinidades: outras palavras. São Paulo: Editora 34, p. 51-77, 2001.

BARDIN, L. Análise de conteúdo. Lisboa: Edições 70, 1977.

CABRAL, C. S. Gravidez na adolescência e identidade masculina: repercussões sobre a trajetória escolar e profissional do jovem. Revista Brasileira de Estudos Popular, v. 19, n. 2, p. 179-96, jun./jul., 2002.

CABRAL, C. S. Contracepção e gravidez na adolescência na perspectiva de jovens pais de uma comunidade favelada do Rio de Janeiro. Caderno de Saúde Pública, Rio de Janeiro, v. 19, supl. 2, 2003.

CABRAL, C. S. Paternidade na trajetória juvenil: uma contribuição ao debate sobre "gravidez na adolescência". In: HEILBORN, M. L.; AQUINO, E. M.; BARBOSA, R. M.; BASTOS, F, I.; BERQUÓ, F.; ROHDEN, F. (org.) Sexualidade, reprodução e saúde. Rio de Janeiro: Fundação Getúlio Vargas, 2009.

CANO, M. A. T.; FERRIANI M. G. C. Sexualidade na adolescência: um estudo bibliográfico. Revista Latino Americana de Enfermagem. v. 8, p. 18-24, 2000.

CORREAA, A. C. P.; FERRIANI, M. G. C. Paternidade na adolescência: um silêncio social e um vazio científico. Revista Gaúcha de Enfermagem, Porto Alegre (RS), v. 27, n. 4, p. 499505, dez, 2006.

CORRÊA, A. C. P.; FERRIANI, M. G. C. Paternidade adolescente: Um Desafio a ser enfrentado pelos serviços de Saúde. Ribeirão Preto, abr. 2007.

DOESCHER, A. M. L.; SOCCI, V.; LEAO, A. M. C.; RIBEIRO, P. R. M. Analisando o comportamento sexual de risco: o conhecimento dos métodos contraceptivos pelos adolescentes. In: Souza, L. L.; Salgado, R. G. (Org.). Infância e juventude no contexto brasileiro: gêneros e sexualidades em debate. 1. ed. Cuiabá: Editora UFMT, p. 133-153, 2012.

HEILBORN, M.; CORDEIRO, F.; MENEZES, R. Desafios e vicissitudes da pesquisa social em sexualidade. In: HEILBORN, M. L; AQUINO, E. M; BARBOSA, R. M; BASTOS, F, I; BERQUÓ, F; ROHDEN, F. (org.) Sexualidade, reprodução e saúde. Rio de Janeiro, Fundação Getúlio Vargas, 2009. 
LEVANDOWSKI, D. C.; PICCININI, C. A. Paternidade na adolescência: aspectos teóricos e empíricos. Revista Brasileira de Crescimento e Desenvolvimento Humano, São Paulo, v. 14, n. 1, 2004.

LYRA, J.; MEDRADO, B.; LOPES, F. Homens também cuidam! Diálogos sobre direitos, saúde sexual e reprodutiva, paternidade e relações de cuidado. Fundo de População das Nações Unidas (UNFPA) e Instituto PAPAI. Recife: UNFPA; Instituto PAPAI, 2007.

MEDRADO, B. O masculino na mídia. Repertórios sobre masculinidade na propaganda televisiva brasileira. Dissertação de mestrado em Psicologia Social. São Paulo: PUC/SP. 1997.

NICOLELLA FILHO, A.; ARNOLDI, M. A. G. C.; ROSA, M. V. F. P. C. Oportunidades Perdidas no Atendimento Integral ao Adolescente: um estudo de caso. Franca: Editora Unifran, 2006.

PAULA, E. R.; BITTAR, C. M.; SILVA, M. A. A paternidade na adolescência e seu significado entre jovens universitários que a vivenciam. São Paulo, nov. 2010.

PINHEIRO, L.; GALIZA, M.; FONTOURA, N. Novos arranjos familiares, velhas convenções sociais de gênero: a licença-parental como política pública para lidar com essas tensões. Revista de Estudos Feministas, Florianópolis, v. 17, n. 3, dez. 2009.

VIEIRA, L. M. et al . Reflexões sobre a anticoncepção na adolescência no Brasil. Revista Brasileira de Saúde Materno Infantil, Recife, v. 6, n. 1, mar. 2006.

VILLELA, W. V.; DORETO, D. T. Sobre a experiência sexual dos jovens. Caderno de Saúde Pública, Rio de Janeiro, v. 22, n. 11, nov. 2006.

\section{Como referenciar este artigo}

FÁVARO, Jéssica Daniele; LEÃO, Andreza Marques de Castro; RIBEIRO, Paulo Rennes Marçal; ZUIN, Luiz Fernando. Paternidade na Adolescência: analisando seu significado, os desafios e suas consequências. Revista Ibero-Americana de Estudos em Educação, Araraquara, v. 14, n. esp. 2, p. 1321-1338, jul. 2019. E-ISSN: 1982-5587. DOI: 10.21723/riaee.v14iesp.2.12582

Submetido em: 30/09/2018

Revisões requeridas: 22/02/2019

Aprovado em: 29/04/2019

Publicado em: 25/06/2019 